\title{
Vasoprotective effects of human CD34+ cells: towards clinical applications
} Thomas J Kiernan1, Barry A Boilson ${ }^{1}$, Tyra A Witt ${ }^{1}$, Allan B Dietz ${ }^{2}$, Amir Lerman ${ }^{1}$ and Robert D Simari*1

\author{
Address: ${ }^{1}$ Division of Cardiovascular Diseases, Mayo Clinic, 200 First Street SW, Rochester, MN 55905, USA and ${ }^{2}$ Division of Transfusion \\ Medicine, Mayo Clinic, 200 First Street SW, Rochester, MN 55905, USA \\ Email: Thomas J Kiernan - kiernan.thomas@mayo.edu; Barry A Boilson - boilson.barry@mayo.edu; Tyra A Witt - witt.tyra@mayo.edu; \\ Allan B Dietz - dietz.allan@mayo.edu; Amir Lerman - lerman.amir@mayo.edu; Robert D Simari* - simari.robert@mayo.edu \\ * Corresponding author
}

Published: 29 July 2009

Journal of Translational Medicine 2009, 7:66 doi:10.1 186/1479-5876-7-66
Received: I May 2009

Accepted: 29 July 2009

This article is available from: http://www.translational-medicine.com/content/7/I/66

(c) 2009 Kiernan et al; licensee BioMed Central Ltd.

This is an Open Access article distributed under the terms of the Creative Commons Attribution License (http://creativecommons.org/licenses/by/2.0), which permits unrestricted use, distribution, and reproduction in any medium, provided the original work is properly cited.

\begin{abstract}
Background: The development of cell-based therapeutics for humans requires preclinical testing in animal models. The use of autologous animal products fails to address the efficacy of similar products derived from humans. We used a novel immunodeficient rat carotid injury model in order to determine whether human cells could improve vascular remodelling following acute injury.

Methods: Human CD34+ cells were separated from peripheral buffy coats using automatic magnetic cell separation. Carotid arterial injury was performed in male Sprague-Dawley nude rats using a $2 \mathrm{~F}$ Fogarty balloon catheter. Freshly harvested $\mathrm{CD} 34+$ cells or saline alone was administered locally for 20 minutes by endoluminal instillation. Structural and functional analysis of the arteries was performed 28 days later.

Results: Morphometric analysis demonstrated that human CD34+ cell delivery was associated with a significant reduction in intimal formation 4 weeks following balloon injury as compared with saline ( $\mathrm{I} / \mathrm{M}$ ratio $0.79 \pm 0.18$, and $\mathrm{I} .7 \mathrm{I} \pm 0.18$ for $\mathrm{CD} 34$, and saline-treated vessels, respectively $\mathrm{P}<$ 0.05). Vasoreactivity studies showed that maximal relaxation of vessel rings from human CD34+ treated animals was significantly enhanced compared with saline-treated counterparts $(74.1 \pm 10.2$, and $36.8 \pm 12.1 \%$ relaxation for $C D 34+$ cells and saline, respectively, $P<0.05$ )

Conclusion: Delivery of human CD34+ cells limits neointima formation and improves arterial reactivity after vascular injury. These studies advance the concept of cell delivery to effect vascular remodeling toward a potential human cellular product.
\end{abstract}

\section{Background}

Cellular therapies hold great promise for the treatment of human disease. The development of cell-based therapeutics for humans requires preclinical testing in animal models. There are inherent limitations to the use of autologous animal products for preclinical testing. First, the use of autologous animal products fails to address the specific efficacy of the intended human product. Second, immunophenotyping of animal products may be limited by a lack of reagents which are available for use in humans and thus fail to predicate human results. To overcome these limitations and in order to develop novel human cellular 
products, immunodeficient animals may be used to test the delivery of these products.

We and others have demonstrated the vasculoprotective effects of local delivery of circulation and adipose-derived cells with an endothelial phenotype following acute vascular injury [1-4]. These effects include a reduction in neointimal formation and improvement in vascular reactivity. These studies suggest that cell delivery may improve large vessel healing which might be extrapolated to clinical scenarios such as post-angioplasty or stenting. However, the translational potential of these studies has been hindered by two important issues. First, the cells have been cultured under variable conditions prior to delivery $[1,2]$. Second, rabbit-specific reagents that define circulating precursors are limited. Thus, identification of a circulating cell capable of these vasoprotective effects would be an advance.

CD34 is a hematopoietic progenitor cell marker. In a landmark publication by Asahara in 1997, bone marrow derived cells expressing CD34 were demonstrated to differentiate ex vivo to an endothelial phenotype [5]. The function of CD34 is uncertain, but it is thought to be a cell to cell adhesion molecule that anchors hematopoeitic progenitor cells to the bone marrow stroma and also facilitates their interaction with other stromal cells. Interestingly, it is also known that there is a complex interaction between bone marrow derived progenitor cells (hematopoetic progenitor cells, HPCs) and microvascular endothelial cells in bone marrow. Endothelial cells appear to regulate the trafficking and release of HPCs from bone marrow [6]. CD34 is also expressed on microvascular endothelial cells, and this shared antigen expression between microvascular endothelium and hematopoietic progenitors is also strongly supportive of a shared embryological origin and that hematopoiesis and vasculogenesis are linked in the embryo. The ability of circulating CD34+ cells to adapt an endothelial phenotype is well established [5]. As such, we aimed to test the hypothesis that delivery of human CD34+ cells would be vasculoprotective. To do so, we developed a model of acute carotid artery injury in an immunodeficient rat model.

\section{Methods \\ Isolation and selection of human CD34+ cells from peripheral blood}

Leukocyte filter eluates (10 mls) of human whole blood were obtained from normal donors after leukophaeresis [7]. Human whole blood samples were obtained from healthy volunteers after approval from the Mayo Clinic Institutional Review Board Approval. The cells were incubated with anti-CD34-conjugated superparamagnetic microbeads (CD34 Isolation kit; Miltenyi Biotec), washed, and processed to obtain purified CD34 cells.
FACS was also performed on freshly immunoselected CD34 cells to determine their phenotypic profile and purity.

\section{Flow cytometry}

Purified cells were counted and re-suspended in seven 100 $\mu \mathrm{L}$ aliquots of PBS for FACS analysis, each containing approximately $10^{5}$ cells. After addition of Fc receptor blocking antibody (Miltenyi Biotec) to each tube, cells were incubated with fluorochrome-conjugated antibodies to CD34 (FITC), CD45 (PerCP) (both from BD biosciences), CD133 (PE) (Miltenyi Biotec), and VEGFR2 (APC) (R\&D Systems). Murine IgG $\mathrm{I}_{1}$ (R\&D Systems) conjugated to Alexa 488, PE (Molecular Probes), and Rat antimouse PerCP (BD Biosciences) was used as isotype controls as well as $\operatorname{IgG}_{1}$-APC from BD Biosciences.

\section{Carotid injury model in immunodeficient rats}

All animal procedures were approved by the Mayo Clinic Institutional Animal Care and Use Committee. Immunodeficient rats (Sprague-Dawley) were housed at constant room temperature $\left(24 \pm 1^{\circ} \mathrm{C}\right)$ and humidity $(60 \pm 3 \%)$. The athymic nude mutant rat (Hsd:RH-Foxn $1^{\wedge}$ rnu) represents a well-established research model that has already made a substantial contribution to many scientific disciplines, such as immunology and cancer research. The rnu allele on chromosome 10 is an autosomal recessive mutation associated with hairlessness and thymic aplasia. The thymus-dependent lymph node areas are depleted of lymphocytes (T-cells). The animals are phenotypically hairless and have rudimentary thymic tissue present. Male e rats ( 3 to 4 months old weighing 350 to $400 \mathrm{~g}$ ) were anesthetized with an intramuscular injection of ketamine 50 $\mathrm{mg} / \mathrm{kg}$, xylazine $10 \mathrm{mg} / \mathrm{kg}$, and acepromazine $1 \mathrm{mg} / \mathrm{kg}$. Under general anaesthesia and by using an operating microscope, a midline incision was made in the neck to expose the left external carotid artery. A 2F Fogarty balloon embolectomy catheter (Baxter) was introduced into the left external carotid artery and advanced through the common carotid artery to the aortic arch. The balloon was inflated with saline $(0.02 \mathrm{ml})$ until a slight resistance was felt and then was rotated while pulling it back through the common carotid artery to denude the vessel of endothelium. This procedure was repeated two more times (total of three passes), and then the catheter was removed. Immediately after catheter withdrawal, residual material was removed and $200 \mu \mathrm{l}$ of saline with freshly selected CD34+ cells and saline alone was administered locally by intra-vascular instillation for 20 minutes through a $24 \mathrm{G}$ catheter. The external carotid was ligated with a 6-0 silk suture and the blood flow restored by removing the clips at the common and internal carotid arteries. After inspection to ascertain adequate pulsation of the common carotid artery, the surgical incision was closed, and the rats were allowed to recover from anaesthesia in a humidified 
and warmed chamber for 2 to 4 hours. The animals were euthanized with an overdose of pentobarbital $(200 \mathrm{mg} /$ kg) 28 days after balloon injury, and the carotid arteries were collected for molecular, mechanical, and histological analyses.

\section{Cell tracking Studies}

In order to track the fate of delivered cells, human CD34+ cells were labelled with CM-DiI $(1 \mu \mathrm{g} / \mathrm{ml})$, a fluorescent membrane dye (Molecular Probes), and resuspended in $200 \mu$ saline for subsequent administration. Animals were euthanized after 4 weeks with an overdose of pentobarbital sodium. Both carotids were excised, embedded in OCT (Tissue-Tek), and immersed in 2-methylbutane cooled by liquid nitrogen. Mounted $5 \mu \mathrm{m}$ sections were examined under fluorescence microscopy for detection of CM-DiI-labeled cells.

\section{Effects of cell delivery on vascular form and function}

Immunodeficient rats were assigned to 3 groups $(n=8$ per group) to determine vasoreactivity and development of neointima formation at 4 weeks after balloon injury. Group 1 rats received no balloon injury and served as uninjured controls. Group 2 rats underwent balloon catheter injury to the left common carotid artery, received human CD34 cells as defined above, and were sacrificed at 4 weeks after balloon injury. Group 3 rats underwent balloon catheter injury to the left common carotid artery, received normal saline, and were sacrificed at 4 weeks after balloon injury.

\section{Arterial vasoreactivity}

Four weeks after balloon injury and local CD34+ cells or saline delivery, animals were euthanized and carotids immediately immersed in cold Krebs solution. Arterial rings $\sim 3 \mathrm{~mm}$ in length (3 per artery) were carefully dissected from the surrounding adipose tissue under a microscope with great care taken to protect the endothelium. The carotid rings were then connected to isometric force displacement transducers and suspended in organ chambers filled with $25 \mathrm{ml}$ of Krebs $\left(94 \% \mathrm{O}_{2}, 6 \% \mathrm{CO}_{2}\right)$ solution. Rings were equilibrated for 1 hour at $37^{\circ} \mathrm{C}$ and then incrementally stretched to $2 \mathrm{~g}$. Viability and maximum contraction was determined with $60 \mathrm{mM} \mathrm{KCl}$. After 3 washes with Krebs solution and further equilibration, arteries were precontracted with phenylephrine in a titrated fashion to achieve $\sim 80 \%$ stable maximal contraction. To study endothelium dependent relaxation, acetylcholine $\left(10^{-9}\right.$ to $\left.10^{-5} \mathrm{M}\right)$ was added to the organ bath in a cumulative manner. Following 3 further washes and equilibration, the arteries were recontracted, and viability was confirmed by assessment of endothelium independent responses to sodium nitroprusside, an exogenous NO donor.

\section{Morphometric analysis}

The carotid arteries were perfusion-fixed at a constant physiological pressure of $125 \mathrm{~mm} \mathrm{Hg}$ with 4\% paraformaldehyde. The carotid arteries were carefully stripped of adventitia and excised between the origin at the aorta and the carotid bifurcation. The proximal segment $(0.3 \mathrm{~cm})$ of the denuded arteries was removed and fixed in $4 \%$ paraformaldehyde for 12 hours before being embedded in paraffin and used for morphometric analysis. The cross sections $(5 \mu \mathrm{m})$ of carotid artery were generated at $200 \mu \mathrm{m}$ intervals, paired slides being then stained with LELVG or $H \& E$ for morphometric analysis. The first three slides (400 $\mu \mathrm{m}$ apart) were analyzed to define the effects on neointimal formation. Endoluminal, internal elastic laminar and external elastic laminar borders were manually traced, digitally measured, and analyzed using software (Image ProPlus) to calculate intimal and medial areas. Because native media thickness is variable (reflecting the diameter of the artery), it was used to index the area of neointima resulting from balloon injury. Accordingly, neointimal thickness was assessed in terms of intima to media area ratios.

\section{Statistical analysis}

Vasoreactivity data were analyzed with ANOVA for repeated measures; direct pair wise comparisons between groups were made with Scheffe's t-test. Intima/Media ratios were compared with unpaired t-tests. A value of $\mathrm{P}<$ 0.05 was considered to be statistically significant. Data are presented as mean \pm SEM.

\section{Results and discussion}

Isolation and characterization of human CD34+ cells

Human CD34+ cells ( 1 to $3 \times 10^{6}$ CD34+ cells) were obtained from normal human donors using two sequential positive magnetic automated cell separations (MACS) immediately upon receipt of blood sample. Freshly isolated CD34+ cells from blood (purity $87 \pm 13 \%$ ) uniformly expressed CD45 $\mathrm{dim}$ while $61 \pm 9 \%$ of cells expressed CD133 and less than 1\% of CD34+ cells were positive for VEGFR2 (Figure 1).

\section{Tracking of delivered human CD34+ cells}

To determine whether delivery of cells resulted in any cell retention for the 4 weeks following delivery, carotid sections were examined under fluorescence microscopy for detection of CM-DiI-labeled cells. Specific red fluorescence identified the presence of labeled human CD34+ cells within the neointima, media, and adventitia of injured segments. No labeled cells were identified in uninjured control arteries. In animals receiving human CD34+ cells, only $12.5 \%$ of carotid sections demonstrated fluorescent luminal endothelial cells at 4 weeks. Labeled cells were seen in the media (Figure 2) but also in the 

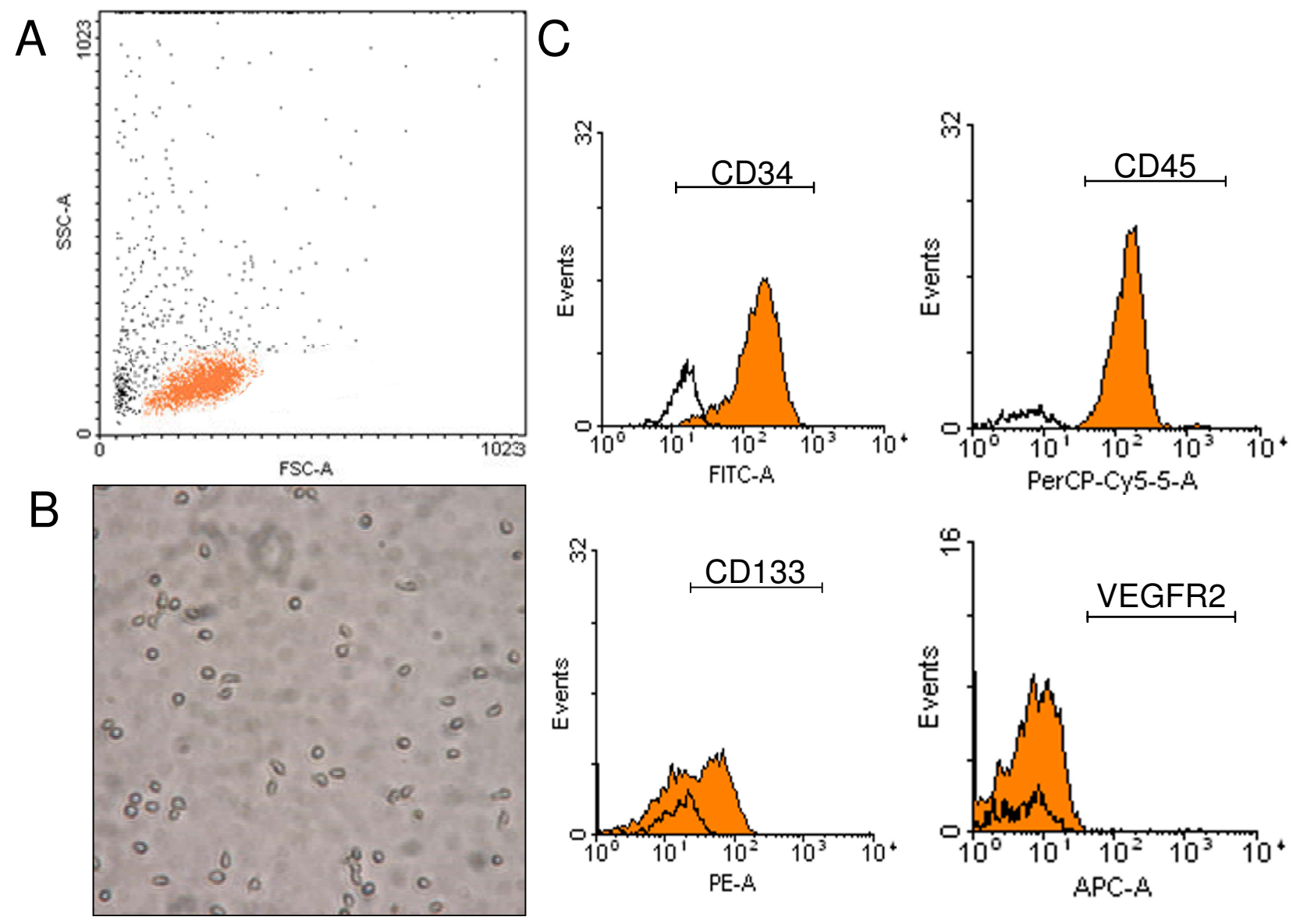

\section{Figure I}

Characterization of human CD34+ cells. A. Scatter analysis reveals a low side scatter and low to intermediate forward scatter population in keeping with small round cells, as shown in (B) photomicrograph (200x). C. FACS analysis of isolated cells. CD34+ cells express CD45dim and CDI33 but not VEGFR2.

neointima and adventitia under fluorescent microscopy. This finding is very consistent with previous findings in circulation-derived cells [1] and suggests a paracrine mechanism for these effects.

\section{Vasculoprotective effects of peripheral human CD34+ cells} Four weeks after balloon injury and local delivery of CD34+ cells or saline, animals were euthanized and carotids immediately immersed in cold Krebs solution. Following pre-contraction with phenylephrine in an organ chamber, relaxation in response to incremental doses of acetylcholine was assessed (Figure 3). Maximal relaxation of vessel rings from human CD34+ treated animals was significantly enhanced compared with saline-treated counterparts $(74.1 \pm 10.2$ and $36.8 \pm 12.1 \%$ relaxation for CD34+ cells and saline, respectively, $P<0.05$ for CD34+ cells vs. saline). The concentration (-Log M) of acetylcholine required to achieve $25 \%$ of maximal relaxation $\left(\mathrm{EC}_{25}\right)$ was $7.19 \pm 0.04$ in CD34 treated animals compared with $5.38 \pm 0.06$ in saline treated animals $(\mathrm{p}<$ 0.005). Although the data clearly demonstrates that CD34+ cell delivery enhanced endothelium dependent vasorelaxation, responses did not achieve those of uninjured vessels which retained the largest responses to acetylcholine ( $\mathrm{p}<0.05$ for maximal relaxation and $\mathrm{EC}_{50}$ compared with CD34 treatment).

Morphometric analysis demonstrated that human CD34+ cell delivery was associated with a significant reduction in neointimal formation 4 weeks following balloon injury as compared with saline. Intima-to-media ratios were $0.79 \pm$ 0.18 , and $1.71 \pm 0.18$ for CD34, and saline-treated vessels, 


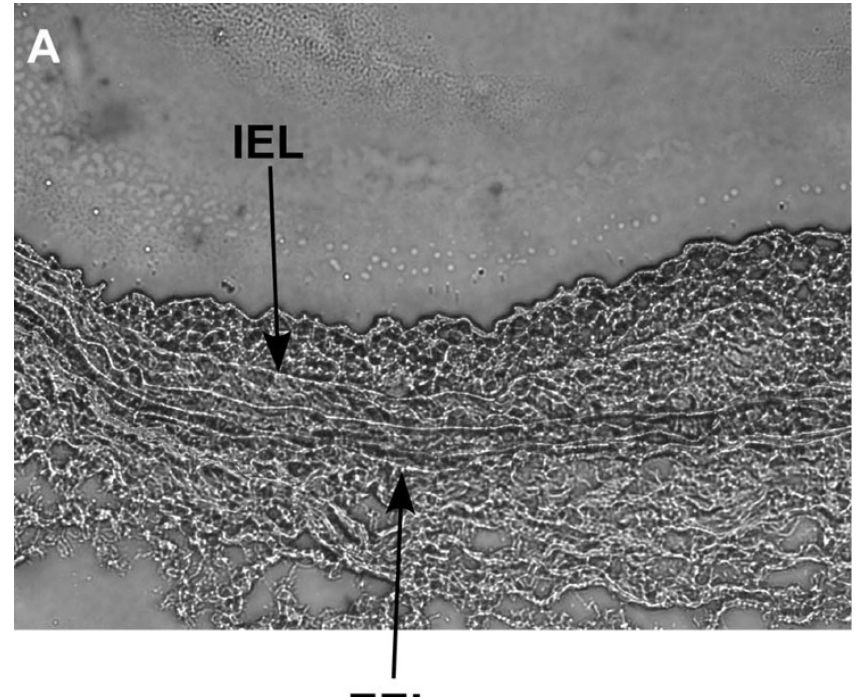

EEL

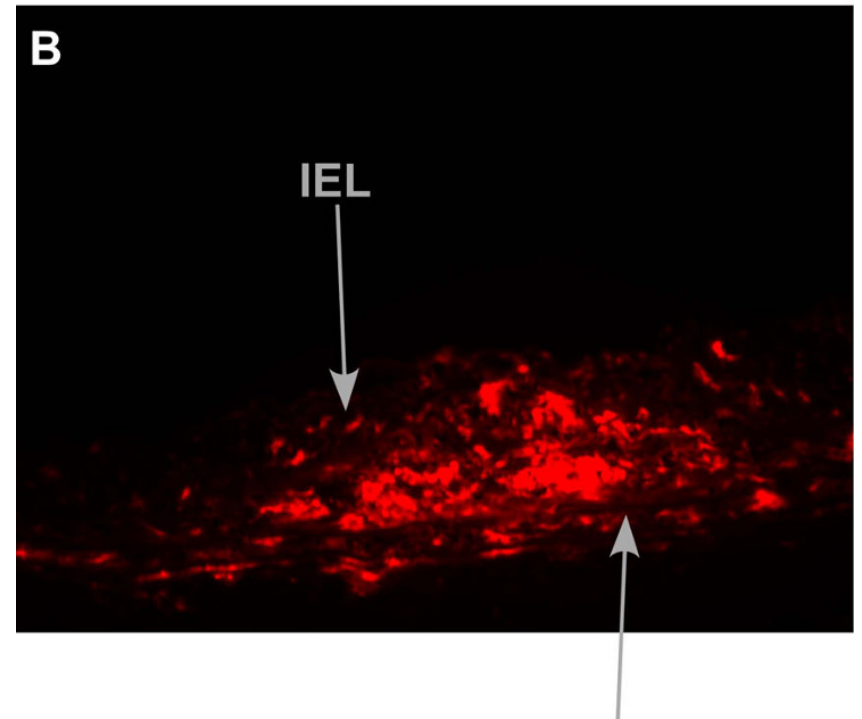

EEL

Figure 2

Tracking of delivered cells. Light microscopy cross section (20x) showing neointima formation in immunodeficient rat carotid 4 weeks after balloon injury $(\mathbf{A})$. CM-Dil-labeled human CD34+ cells stain red under fluorescent microscope (20x) within intima and media of carotid 4 weeks after balloon injury (B). IEL = Internal elastic lamina, EEL = external elastic lamina.

respectively ( $\mathrm{P}<0.05$ for $\mathrm{CD} 34$ vs. saline treated vessels) (Figure 4). This suggests that, in addition to improving endothelium-dependent relaxation, local delivery of CD34+ cells also attenuated neointimal formation after arterial injury in this immunodeficient rat model.

\section{Why CD34 + cells?}

Endothelial progenitor cells (EPCs) are the most studied vascular progenitors [8]. New understandings of the

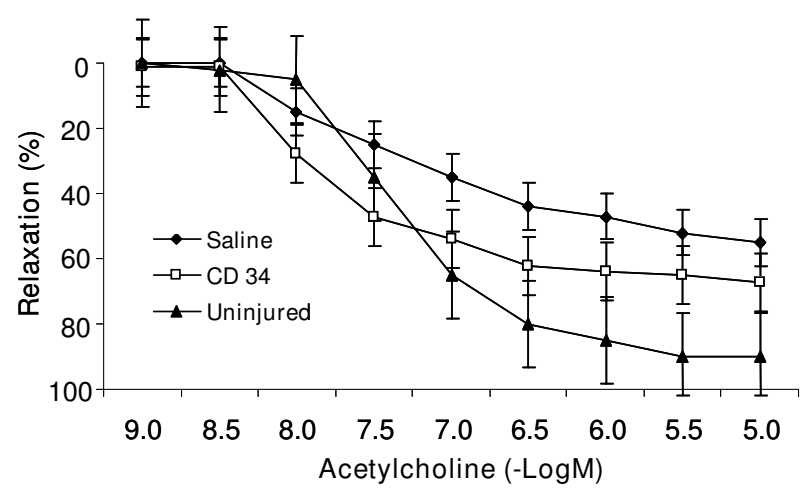

\section{Figure 3}

Cell delivery improves vasoreactivity. Human CD34+ cell delivery improves endothelium-dependent vasoreactivity after arterial injury. Carotid rings from CD34+ cell treated rats (open squares) show markedly enhanced vasoreactivity to acetylcholine 4 weeks after injury compared to saline controls (diamonds) $(P<0.05$ for CD34+ cells vs. saline). However, uninjured left carotid arteries retained the largest relaxation responses $(P<0.05$, vs. CD34+ treated rings). Values are means \pm SE. $n=8$ /group.

inherent role of circulating cells, including precursor cells, in postnatal neovascularization have presented novel therapeutic opportunities. Studied applications of endothelial-lineage cell therapy have demonstrated enhancement of new capillary formation in ischemic tissue (therapeutic vasculogenesis) and generation of an anti-thrombogenic luminal surfaces in prosthetic grafts [9-13].

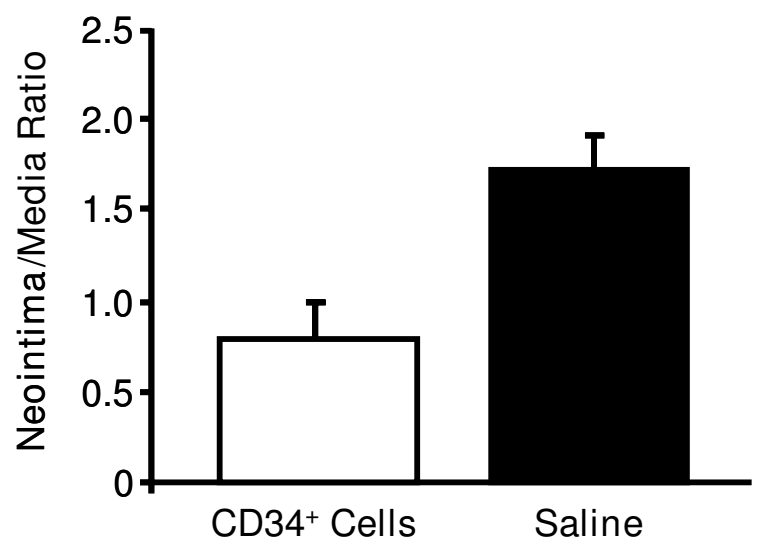

\section{Figure 4}

Cell delivery reduces neointimal formation. Local delivery of human CD34+ cells reduces neointimal formation after balloon injury. Significant attenuation of intima-to-media ratio in CD34+ treated vessels compared with saline treated control groups 4 weeks after injury $(P<0.05$ for CD34+ cells vs. saline). $n=8 /$ group. 
The current study tested whether specifically selected fresh human CD34+ cells without culture modification may have an applied role in modulating the vascular response to balloon injury. Unfortunately, no single definition of vascular progenitor cells exists, and it is unknown which is the best antigenic profile to identify progenitor cells linked to vascular and endothelial disease. Additionally, it is unclear as to what defines the best cells for vasculoprotective delivery. Performance of these studies necessitated the use of human reagents and an immunodeficient model. Therefore, this current study using freshly derived cells of surface antigens, represents a valid alternative of cellular therapy for vascular disease being time-saving, inexpensive, precise, and reproducible. Also, this reagent has been used extensively in humans for transplantation with an excellent safety profile.

The finding of delivered cells over a small proportion of the luminal surface suggests direct but incomplete participation of $\mathrm{CD} 34+$ cells in endothelial re-surfacing. Although the proportion may have been underestimated due to loss of fluorescence with cell division, it should not have been to such an extent as seen in our study. Thus, indirect mechanisms may also be involved. CD34+ cell incorporation may alter the kinetics of the denuded surface to induce proliferation of neighboring resident endothelium or recruit additional circulating precursors. In support of this possibility, it has been shown that BMendothelial lineage cells express angiogenic ligands and cytokines $[14,15]$ and induce proliferation of preexisting vasculature in the vicinity of myocardial infarcts [16].

The margin by which CD34+ cell delivery improved endothelial-dependent vasoreactivity is an important feature of this study. The effect is likely to be mediated at least in part by accelerated re-endothelialization. However, non-luminally located cells (as were also found in this study) could additionally influence vascular reactivity through paracrine mechanisms including the release of nitric oxide (NO) into the surrounding milieu. Indeed, adenoviral gene transfer of eNOS to the adventitia has been shown to improve NO production and vasoreactivity even in arteries without endothelium [17]. The benefit conferred by CD34+ cell delivery was seen after 28 days. It is also compatible with a paracrine hypothesis as outlined above, but the relative contribution of direct and indirect cell effects remain to be determined.

\section{Conclusion}

The vasoprotective effects of freshly isolated human CD34+ cells without in vitro manipulation have been demonstrated in this novel animal model of carotid injury. Improvement in arterial vasoreactivity and decrease in neointima formation was observed in conjunction with delivery of selected CD34+ cells. This pre- clinical model has important implications for translational studies to clinical medicine.

\section{Competing interests}

The authors declare that they have no competing interests.

\section{Authors' contributions}

TK designed and performed the animal studies and analysis. BB designed and performed the animal studies and analysis. TW provided technical expertise for the animal studies. AD provided expertise and support for the cell isolation procedures. AL performed the vascular reactivity studies. RS provided the conceptual framework, designed the studies, and reviewed the analysis. The manuscript was written and approved by all members of the team.

\section{Acknowledgements}

Manuscript was funded by NIH HL75566 (RDS).

\section{References}

I. Gulati R, Jevremovic D, Peterson TE, Witt TA, Kleppe LS, Mueske CS, Lerman A, Vile RG, Simari RD: Autologous culture-modified mononuclear cells confer vascular protection after arterial injury. Circulation 2003, 108:1520-1526.

2. Gulati R, Jevremovic D, Witt TA, Kleppe LS, Vile RG, Lerman A, Simari RD: Modulation of the vascular response to injury by autologous blood-derived outgrowth endothelial cells. Am J Physiol Heart Circ Physiol 2004, 287: H5 I 2-5 I7.

3. Griese DP, Ehsan A, Melo LG, Kong D, Zhang L, Mann MJ, Pratt RE, Mulligan RC, Dzau VJ: Isolation and transplantation of autologous circulating endothelial cells into denuded vessels and prosthetic grafts: implications for cell-based vascular therapy. Circulation 2003, 108:2710-2715.

4. Froehlich $H$, Gulati R, Boilson B, Witt T, Harbuzariu A, Kleppe L, Dietz AB, Lerman A, Simari RD: Carotid Repair Using Autologous Adipose-Derived Endothelial Cells. Stroke 2009, 40(5): $|886-9|$.

5. Asahara T, Murohara T, Sullivan A, Silver M, Zee R van der, Li T, Witzenbichler B, Schatteman G, Isner J: Isolation of putative progenitor endothelial cells for angiogensis. Science 1997, 275:964-967.

6. Mohle R, et al:: Transendothelial migration of CD34+ and mature hematopoietic cells: an in vitro study using a human bone marrow endothelial cell line. Blood 1997, 89(1):72-80.

7. Dietz AB, Bulur PA, Emery RL, Winters JL, Epps DE, Zubair AC, VukPavlovic S: A novel source of viable peripheral blood mononuclear cells from leukoreduction system chambers. Transfusion 2006, 46:2083-2089.

8. Urbich C, Dimmeler S: Endothelial progenitor cells: characterization and role in vascular biology. Circ Res 2004, 95:343-353.

9. Assmus B, Schachinger V, Teupe C, Britten M, Lehmann R, Dobert N, Grunwald F, Aicher A, Urbich C, Martin H, et al.: Transplantation of progenitor cells and regeneration enhancement in acute myocardial infarction (TOPCARE). Circulation 2002, 106:3009-3017.

10. Kalka C, Masuda H, Takahashi T, Kalka-Moll WM, Silver M, Kearney $\mathrm{M}$, Li T, Isner JM, Asahara T: Transplantation of ex vivo expanded endothelial progenitor cells for therapeutic neovascularization. PNAS 2000, 97:3422-3427.

II. Kawamoto A, Gwon H-C, Iwaguro H, Yamaguchi J-I, Uchida S, Masuda $\mathrm{H}$, Silver M, Ma H, Kearney M, Isner J, Asahara T: Therapeutic potential of ex vivo expanded endothelial progenitor cells for myocardial ischemia. Circulation 200I, 103:634-637.

12. Schatteman G, Hanlon H, Jiao C, Dodds S, Christy B: Blood-derived angioblasts accelerate blood-flow restoration in diabetic mice. Journal of Clinical Investigation 2000, 106:57I-578.

13. Kaushal S, Amiel GE, Guleserian KJ, Shapira OM, Perry T, Sutherland FW, Rabkin E, Moran AM, Schoen FJ, Atala A, et al.: Functional 
small-diameter neovessels created using endothelial progenitor cells expanded ex vivo. Nat Med 200I, 7:1035-1040.

14. Schmeisser A, Garlichs CD, Zhang H, Eskafi S, Graffy C, Ludwig J, Strasser RH, Daniel WG: Monocytes coexpress endothelial and macrophagocytic lineage markers and form cord-like structures in Matrigel and angiogenic conditions. Cardiovascular Research 200I, 49:67I-680.

15. Kamihata H, Matsubara H, Nishiue T, Fujiyama S, Tsutsumi Y, Ozono R, Masaki H, Mori Y, Iba O, Tateishi E, et al.: Implantation of bone marrow mononuclear cells into ischemic myocardium enhances collateral perfusion and regional function via side supply of angioblasts, angiogenic ligands, and cytokines. Circulation 200I, 104: I046-1052.

16. Kocher AA, Schuster MD, Szabolcs MJ, Takuma S, Burkhoff D, Wang J, Homma S, Edwards NM, Itescu S: Neovascularization of ischemic myocardium by human bone-marrow-derived angioblasts prevents cardiomyocyte apoptosis, reduces remodeling and improves cardiac function. Nature Medicine 200I, 7:4I2-430.

17. Kullo I, Mozes G, Schwartz R, Gloviczki P, Crotty T, Barber D, Katusic Z, O'Brien T: Adventitial gene transfer of recombinant endothelial nitric oxide synthase to rabbit carotid arteries alters vascular reactivity. Circulation 1997, 96:2254-2261.

Publish with Bio Med Central and every scientist can read your work free of charge

"BioMed Central will be the most significant development for disseminating the results of biomedical research in our lifetime. "

Sir Paul Nurse, Cancer Research UK

Your research papers will be:

- available free of charge to the entire biomedical community

- peer reviewed and published immediately upon acceptance

- cited in PubMed and archived on PubMed Central

- yours - you keep the copyright 